[3] Thermal properties of petroleum products, NBS Misc. Pub. M97 (1929).

[4] D. D. Wagman and F. D. Rossini, A note on the macroanalysis of carbon and hydrogen by combustion, J. Research NBS 32, 95 (1944) RP1577.
[5] Martin Shepherd, An improved apparatus and method for the analysis of gas mixtures by combustion and absorption, BS J. Research 6, 121 (1931) RP266.

[6] Martin Shepherd, Rapid determination of small amounts of carbon monoxide, Anal. Chem. 19, 77 (1947).

Washington, February 13, 1950.

\title{
Absorption of Near-Infrared Energy by Certain Glasses
}

\author{
By Jack M. Florence, Charles C. Allshouse, Francis W. Glaze, and Clarence H. Hahner
}

\begin{abstract}
An analysis has been made of the absorption bands of various glasses by calculation of the internal transmittances and surface losses. The wavelengths, in microns, associated with broad absorption bands have been measured, and the active vibrating groups causing the absorption are as follows: $2.7, \mathrm{CO}_{2} ; 2.75, \mathrm{OH} ; 2.75, \mathrm{CO}_{2} ; 2.9, \mathrm{OH}$ associated $; 3.5, \mathrm{CO}_{3}^{--}$; 3.65, $\left(\mathrm{NO}_{3}{ }^{-}\right) ; 3.8, \mathrm{Si}-\mathrm{O}$ bond; 4.0, $\mathrm{CO}_{3}^{--} ; 4.15,\left(\mathrm{NO}_{3}^{-}\right) ; 4.25, \mathrm{CO}_{2} ; 4.45, \mathrm{Si}-\mathrm{O}$ bond; and 4.7, OH associated. The greatest loss of infrared energy for a number of glasses is caused by surface losses, rather than by true internal absorption.
\end{abstract}

\section{Introduction}

\section{Gaseous Components of Glasses}

Glasses contain, in solution and as bubbles, small amounts of gaseous components. These are residues of the decomposition products of the original batch materials or the result of contact with the furnace atmosphere. The gaseous components in the body of the glass may be considered as present in two conditions: namely, in true solution and as a part of the internal structure. The internal transmittances for any glass, when plotted against wavelength, will contain absorption bands in the region of the spectrum in which these gases absorb. The intensity of the absorption bands depends upon the concentration and the absorbing power of the gas.

Because the surfaces of many glasses are chemically active toward the atmosphere, they also become of importance in the transmission of nearinfrared energy. Weyl $[1]^{2}$ explains that the configuration of the ions in the surface layer of a glass is not identical with that in the internal structure. He has explained the presence of $\mathrm{OH}^{-}$in a glass as being a surface phenomenon. The surface of silica glass has a film of $\mathrm{OH}^{-}$formed from the hydrolysis of Si-O-X bonds, where $\mathrm{X}$ is either an alkali or an alkaline earth ion. The $\mathrm{X}$ forms a water soluble salt that is leached out and replaced by a hydroxonium ion $\left(\mathrm{H}_{3} \mathrm{O}^{+}\right)$. The surface contains those $\mathrm{Si}-\mathrm{O}-\mathrm{Si}$ bonds that were originally present in the glass and a number of the $\mathrm{Si}-\mathrm{OH}$ groups.

The above explanation may be carried further by $\mathrm{X}$ forming first a hydroxide and then a carbonate. Taking a lithium silicate glass as an example, it follows:

\footnotetext{
1 This project was supported by the Department of the Navy, Bureau of Ships.
}

Figures in brackets indicate the literature references at the end of this paper

$$
\begin{aligned}
-\mathrm{Si}-\mathrm{O}-\mathrm{Li}+2 \mathrm{HOH} & \longrightarrow \mathrm{SiO}-\mathrm{OH}_{3}+\mathrm{LiOH} \\
-\mathrm{SiO}-\mathrm{OH}_{3} & \longrightarrow \mathrm{SiOH}+\mathrm{HOH} \\
2 \mathrm{LiOH}+\mathrm{CO}_{2} & \longrightarrow \mathrm{Li}_{2} \mathrm{CO}_{3}+\mathrm{HOH}
\end{aligned}
$$

The products of the reaction, plus any sorbed water from the atmosphere, remain on or near the surface of the glass.

Roman, Marboe, and Weyl also found that glass surfaces containing $\mathrm{Ba}^{++}$and $\mathrm{Pb}^{++}$ions, among others, showed decreasing hygroscopicity with decreasing ionic potential [2]. It has been found that glasses containing $\mathrm{BaO}$ and $\mathrm{PbO}$ have a high transmissivity for infrared energy for wavelengths of 2.5 to $4.5 \mu[3,4]$.

\section{Characteristic Wavelengths of the Vibrating Groups}

The identification of the vibrating groups has been made from the knowledge of the gaseous components that may be expected to be in a glass and their characteristic wavelengths. It has been possible to identify the vibrating groups to be expected in a glass through a knowledge of the decomposition products of the batch materials used and their characteristic absorption bands. The precise location of the wavelengths at which these absorption bands occur has been amply discussed by Herzberg [5].

The wavelength of the fundamental vibration of $\mathrm{OH}$ in water vapor has been identified at $2.66 \mu$. The hydroxyl vibration becomes broader and stronger and moves to a longer wavelength when "hydrogen bonding" occurs [5]. The substitution of a silicon atom for one of the hydrogen atoms of the $\mathrm{HOH}$ dipole also creates a difference in the internuclear distance of the $\mathrm{OH}$ bond, thereby changing the observed wavelength for this vibration. The wavelength for the $\mathrm{OH}$ vibration in the vapor phase, obtained from glasses, is $2.75 \mu$. When the water is 
in the liquid state, the characteristic vibrations occur at wavelengths of $2.9,4.7$, and $6.25 \mu$ [6]. Dorsey gives the wavelengths from several sources as 2.663 $\mu$ for the vapor phase, and $2.97 \mu$ for the liquid phase for pure water [7].

Any caronate ion $\left(\mathrm{CO}_{3}^{-{ }^{-}}\right)$that may be absorbed on a glass surface will have characteristic absorption bands. It has strong absorption bands at about 3.5 and $4.0 \mu$, which is in the region of absorption by the first harmonic of the intense fundamental vibration at $6.8 \mu$, that shift with the increase or decrease in equivalent weight of the metallic cation. The composite transmission curve for salts containing this ion (fig. 1) was prepared from the data of Coblentz [8] and of Schaefer, Bormuth, and Matossi [9]. Carbon dioxide gas $\left(\mathrm{CO}_{2}\right)$ has absorption bands at $2.7,2.75$, and $4.25 \mu$ and may be identified by the 4.25-absorption band [5].

The transmittance curves for salts containing the nitrate ion $\left(\mathrm{NO}_{3}{ }^{-}\right)$(fig. 2) show absorption bands at approximately the same wavelength as those for the carbonate ions $[8,10]$. The fundamental vibration of shortest wavelength for the nitrate ion occurs at $7.25 \mu$, the band occurring at $3.65 \mu$ being the first harmonic of this vibration.

\section{Absorption of Glasses}

A recent publication has identified the absorption of near-infrared energy at wavelengths of 2.7 to 3.0 $\mu$ as the $\mathrm{OH}^{-}$vibrational absorption introduced by the water content of the glass [11]. Glasses do not show fine line structure of absorption in the infrared, but rather wide regions of absorption and transparency. This has led to the general conclusion that the absorption of energy at wavelengths of 3.0 to 4.0 $\mu$ is influenced by the water-absorption band. Further identification of this absorption region is attempted in this paper. Also, a method is presented for the determination of the behavior of certain glasses in the near-infrared region and, from such data, the specific absorption bands may be more easily identified.

\section{Preparation and Measurement of the Glasses}

The glasses, with the exception of the fused silica and Pyrex glass No. 774 samples, were prepared for this work and were melted in platinum crucibles of 300 - to 500-g capacity. The batch materials, in most cases, were those used in the production of precision optical glass; hence they were of high commercial purity. No attempt was made to further purify these materials prior to use. The only metallic oxide believed to be present in sufficient quantities to affect the transmission was iron. The amount of iron present, as $\mathrm{Fe}_{2} \mathrm{O}_{3}$, in the glass is estimated to be less than 0.02 percent. Its presence is shown by an absorption band at or near $1.0 \mu$ (fig. 13).

The glasses were melted and fined in either a platinum resistance or a Globar furnace in about $6 \mathrm{hr}$ and then poured into steel molds to form samples approximately $1 / 2$ in. thick. The quality of the samples generally equaled that of the requirements for optical glass. Samples were prepared for measurement by grinding and polishing into plates, with plane parallel faces, 2 in. square.

The spectral transmittances from $2 \mu$ and beyond were determined by a Baird automatic infrared spectrometer. Where values below $2 \mu$ are reported, these data were determined radiometrically by means of a fluorite prism mirror spectrometer, Nernst glower, and a vacuum thermopile. All of the infrared transmission data was supplied by the Radiometry Section of the Bureau.

The compositions of the glasses discussed in this paper are given in table 1.

TaBle 1.-Glass Composition

(weight percent)

\begin{tabular}{|c|c|c|c|c|c|c|c|c|c|c|c|}
\hline Glass type & $\mathrm{SiO}_{2}$ & $\mathrm{~B}_{2} \mathrm{O}_{3}$ & $\mathrm{Li}_{2} \mathrm{O}$ & $\mathrm{Na}_{2} \mathrm{O}$ & $\mathrm{K}_{2} \mathrm{O}$ & $\mathrm{BeO}$ & $\mathrm{BaO}$ & $\mathrm{PbO}$ & $\mathrm{Al}_{2} \mathrm{O}_{3}$ & $\mathrm{Cr}_{2} \mathrm{O}_{3}$ & $\mathrm{MnO}_{2}$ \\
\hline Fused silica & 100.00 & & & & & & & & & & \\
\hline $\begin{array}{l}\text { Lithium silicate-.. } \\
\text { Lithiumm-ervllium silicate }\end{array}$ & 80.72 & & 19. 26 & & & & & & & & \\
\hline $\begin{array}{l}\text { Lithium-beryllium silicate } \\
\text { Sodium-barium silicate... }\end{array}$ & $\begin{array}{l}84.53 \\
40.00\end{array}$ & & 8.42 & 20.00 & & 7.05 & 40.00 & & & & \\
\hline $\begin{array}{l}\text { Potassium silicate } \\
\text { Pyrex No 774 [14] }\end{array}$ & 70.00 & & & & 33.00 & & & & & & \\
\hline $\begin{array}{l}\text { Pyrex No. } 774[14] \\
\text { NBS-IR-1. }\end{array}$ & $\begin{array}{l}80.5 \\
48.16\end{array}$ & 12.9 & & $\begin{array}{l}3.8 \\
9.94\end{array}$ & 0.4 & & & 35.80 & 2. 2 & 5.63 & 0.47 \\
\hline
\end{tabular}

\section{Calculation of Internal Transmittances}

Because the absorption of near-infrared energy by glasses may, in part, be a surface phenomenon, it becomes highly desirable to determine the internal transmittance of the glass itself. A method used for the determination of the transmittance of visible light for optical glass, and also used by Rubens for the infrared spectra, is to measure the total trans-

Total transmittance, as used in this paper, means the percentage of incident energy emerging perpendicular to the surface of the sample and parallel to the direction of propagation of the enregy. mittance ${ }^{3}$ for two thicknesses of a given glass sample [12].

The total transmittance of a sample of glass is defined as

$$
T=(1-S)^{2} T_{i}{ }^{4}
$$

\footnotetext{
4 George W. Morey, The properties of glass, p. 367. (Reinhold Publishing Corp., New York, N.' Y., 1938). This can be proved as follows: The energy entering the glass is $(1-\dot{S})$. If $\left(1-T_{i}\right)$ is the internal absorptance of the glass entering the glass is $(1-S)$. If $\left(1-T_{i}\right)$ is the internal absorptance of the glass
sample, the energy reaching the second surface is $(1-S)-(1-S)\left(1-T_{i}\right)$. Then, sample, the energy reaching the second surface is $(1-S)-(1-S)\left(1-T_{i}\right)$. Then,
the energy leaving the glass is $(1-S)-(1-S)\left(1-T_{i}\right)-\left[(1-S)-(1-S)\left(1-T_{i}\right)\right] S$, which is equal to $T$. So $T=(1-S)\left(1-1+T_{i}\right)-(1-S)\left(1-1+T_{i}\right) S$ $=(1-S) T_{i}(1-S)$ $=(1-S)^{2} T_{i}$

It must be remembered that the above derivation does not take into account
} multiple reflection, which may produce an appreciable error. 
where $T$ is the total transmittance, $T_{i}$ the internal transmittance, $S$ the fractional surface loss at, and $(1-S)$ the fraction transmitted through, one surface of the sample. Then, for two thicknesses of the same glass

and

$$
\frac{T_{1}}{T_{2}}=\frac{(1-S)^{2} T_{i_{1}}}{(1-S)^{2} T_{i_{2}}}=\frac{T_{i_{1}}}{T_{i_{2}}},
$$

$$
\log T_{1}-\log T_{2}=\log T_{i_{1}}-\log T_{i_{2}},
$$

where the subscripts 1 and 2 indicate the thin and thick samples, respectively. According to Lambert's law,

$$
-\log T_{i}=a_{i} b
$$

where $a_{i}{ }^{5}$ is the internal absorbance index, and $b$ is the thickness in millimeters. Therefore, $\log T_{1}-$ $\log T_{2}=-a_{i} b_{1}+a_{i} b_{2}=a_{i}\left(b_{2}-b_{1}\right)$, and solving for $a_{i}$,

$$
a_{i}=\frac{\log T_{1}-\log T_{2}}{b_{2}-b_{1}}
$$

The internal transmittance, $T_{i_{3}}$, can then be calculated from the absorbance index for any given thickness, $b_{3}$, by means of the following:

$$
T_{i_{3}}=\operatorname{antilog}\left(-a_{i} b_{3}\right) .
$$

The loss of energy at one surface of the sample by reflection, scattering and absorption of the film is obtained from the equation

$$
S=1-\left(\frac{T}{T_{2}}\right)^{1 / 2}
$$

The above equation is based on the assumption that the surface losses for samples of the same glass, but of different thicknesses, are the same. Calculations of absorbance indices from several thicknesses of the same melt of glass (NBS-IR-1) vary, but the curves drawn from these data tend to show the same maxima.

The above method of calculating the internal absorbance index of a glass is not too accurate when the total absorbance $\left(-\log T_{i}\right)$ is small or is changing rapidly. In part, this is due to the degree of accuracy of the infrared spectrometer, which is of the order of \pm 1 percent; also, instrument lag in the automatic instruments, shifts caused by temperature variations within the spectrometer, etc., enter into the picture.

The results obtained by the preceding method are not reproducible when applied to glasses of high hygroscopicity, such as those of some of the binary systems, because of the changes in water sorbed during preparation and measurement of the samples. These data should only be used qualitatively to show

\footnotetext{
3 The nomenclature used follows closely that of NBS Letter Circular LC85? (May 19, 1947).
}

absorption bands and regions of high surface loss when comparing two different glasses. Recent evidence indicates that more consistent results are obtained with fused silica and complex glasses of low hygroscopicity. ${ }^{6}$

\section{Absorption for Wavelengths from 2.7 to 3.0 Microns}

The fused silica sample reported in a previous paper [3] had an absorption band at 2.74 to $2.80 \mu$ (fig. 3), which could be either $\mathrm{OH}$ or $\mathrm{CO}_{2}$. Subsequent measurements on two fused silica samples of different thicknesses (fig. 4) have shown this band as occurring at $2.75 \mu$. The binary glass of lithium silicate (fig. 5) has an absorption band at $2.9 \mu$, indicating that the water contained by this glass is predominantly in the liquid phase.

The absorption band of the water, in the liquid phase, in a glass is so strong that it usually overlaps the absorption band for water in the vapor phase. However, in an experimental glass of the composition $\mathrm{Li}_{2} \mathrm{O} \cdot \mathrm{BeO} \cdot 5 \mathrm{SiO}_{2}$ (fig. 6), the two bands at 2.75 and $2.9 \mu$ appear almost equal in intensity for the particular sample measured. The absence of the 4.25 band $\left(\mathrm{CO}_{2}\right)$ eliminates the possibility that the 2.75 band might also be caused by $\mathrm{CO}_{2}$. It is suggested that the $2.75-\mu$ band represents water in the vapor phase. However, this should not be considered as a proof of its existence, as it is possible that certain constituents of this glass might have weak bands in this region.

\section{Absorption for Wavelengths Longer Than 3.0 Microns}

The carbonate ion has two strong absorption bands (at 3.5 and $4.0 \mu$ ) that shift with the increase or decrease in equivalent weight of the metallic cation. In figure 5 the lithium silicate glass has absorption bands at 3.5 and $4.0 \mu$, corresponding to those of the carbonate ion. However, the mere presence of absorption bands at 3.5 and $4.0 \mu$ is not positive identification of the carbonate ion, since the nitrate ion absorption bands occur at approximately the same wavelengths. The batch ingredients must be known before these absorption bands can be positively associated with the carbonate ion alone. An example of the 4.25 band for carbon dioxide is shown in figure 7 for a glass of the sodium-barium silicate system made from a batch containing both sodium carbonate and barium carbonate. This band has also been observed on a number of other glasses made from batch materials containing carbonates.

The substitution of nitrates for carbonates in the glass batch improves the transmission of infrared energy of the resulting glass. This is very evident from a comparison of figure $8, \mathrm{~A}$ and $\mathrm{B}$. The glass from which the internal transmittance curves in figure 8 , A were obtained was made with potassium carbonate in its batch; that from which the curves in

${ }^{6}$ The hygroscopicity of a glass may be determined by the method of Hubbard, J. Research NBS 36, 365 (1946) RP1706. 
figure $8, \mathrm{~B}$ were obtained was made with potassium nitrate. The total ionic charge of the carbonate ions in the one batch was made equal to the total ionic charge of the nitrate ions in the other batch. The 3.5- and 4.0- $\mu$ absorption bands for $\mathrm{CO}_{3}{ }^{--}$in the first instance and the 3.65 and 4.15 bands for $\mathrm{NO}_{3}{ }^{-}$in the second are evident. These curves show rather conclusively that the $\mathrm{CO}_{3}{ }^{--}$is a much stronger absorbent of infrared energy than the $\mathrm{NO}_{3}{ }^{-}$. The carbonate ion also produces greater surface losses.

Fused silica has strong absorption bands at 3.8 and $4.45 \mu$, as indicated in figures 3 and 4 . These two absorption bands are caused by the silicon-oxygen bond [11] and are of sufficient intensity to be identified in more complex glasses.

In the following tabulation the above absorption bands observed for glasses are listed by wavelengths and vibrating groups for reference:

\begin{tabular}{|c|c|c|c|}
\hline Wavelength & Vibrating group & Wavelength & Vibrating group \\
\hline $\begin{array}{l}\text { Microns } \\
2.7 \\
2.75 \\
2.75 \\
2.9 \\
3.5 \\
3.65\end{array}$ & $\begin{array}{l}\mathrm{CO}_{2} \\
\mathrm{OH}^{-} \\
\mathrm{CO}_{2} \\
\mathrm{OH} \text { associated } \\
\mathrm{CO}_{3}{ }^{--} \\
\mathrm{NO}_{3}^{-}\end{array}$ & $\begin{array}{l}\text { Microns } \\
3.8 \\
4.0 \\
4.15 \\
4.25 \\
4.45 \\
4.7\end{array}$ & $\begin{array}{l}\mathrm{Si}-\mathrm{O} \text { bond } \\
\mathrm{CO}_{3}^{--} \\
\mathrm{NO}_{3}^{-} \\
\mathrm{CO}_{2} \\
\mathrm{Si}-\mathrm{O} \text { bond } \\
\mathrm{OH} \text { associated }\end{array}$ \\
\hline
\end{tabular}

\section{Individual Glasses}

\section{Fused Silica}

In figure 4 the two transmittance curves for two thicknesses of fused silica are shown with a curve for the calculated internal transmittance. Figure 4 also shows the calculated surface losses. The curves show the following absorption bands: $2.75,3.0,3.5$, $3.8,4.0,4.45$, and $4.7 \mu$. With the exception of the $2.75-, 3.5-, 4.0-$ and $4.7-\mu$ bands, these absorption bands more or less coincide with the stronger bands of crystalline quartz [13]. The absorption bands at 3.5 and $4.0 \mu$ might indicate the presence of a small amount of the carbonate ion. The absorption band of silica at $4.45 \mu$ is very definite. It is important to note that apparently the $\mathrm{OH}$ is present in the internal structure of the glass, as indicated by the internal transmittances and the absence of an increase in surface losses in the region of $2.75 \mu$.

\section{2. $\mathrm{K}_{2} \mathrm{O}-\mathrm{SiO}_{2}$ Glass}

The calculation of the internal transmittances and the surface losses for a glass from the potash-silica system shows that the greater loss of energy is at the surface of the glass. These results are plotted in figure $8, \mathrm{~A}$ and $\mathrm{B}$. The internal transmittance curves show considerable absorption for wavelengths longer than $2.7 \mu$. indicating that some of the absorbing media is contained in the internal structure of the glass. The curves for the surface losses indicate the presence of carbonate ions and nitrate ions on or near the surface. The magnitude of the surface losses appears to be greater than that which could be reasonably attributed to reflection by the glass alone. This glass is, therefore, unsuitable for the transmission of infrared energy.

\section{Corning Pyrex glass No. 774}

The samples of untreated and vacuum-degassed Pyrex glass No. 774 used by Harrison [11] were measured at this Bureau in 1935. Applying the mathematical analysis to these data gives the transmittance curves shown in figures 9,10 , and 11 . These curves indicate that the $\mathrm{OH}$ is present. A comparison of the internal transmittances for two samples, shown in figure 11, indicates that the vacuum treatment at the temperatures used considerably improved the internal transmittance of the glass; figure 12 shows that the treatment practically removed the surface loss caused by the $\mathrm{OH}$. It seems, therefore, that the presence of the $\mathrm{OH}$, is in part, a surface phenomenon, corroborating Weyl's statement [1].

\section{IR Filter No. 1}

Filter glass NBS-IR-1, developed for the Bureau of Ships, Department of the Navy, absorbs the visible spectrum but has a high transmittance of the nearinfrared energy. The transmittance curves for this glass, figure 13 , show the absorption bands in the tabulation above, including the band for $\mathrm{CO}_{2}$ at $4.25 \mu$. This $\mathrm{CO}_{2}$ absorption is indicated by the internal transmittance curve. The surface losses, shown in figure 13 , indicate very little water on the surface of the glass. These data indicate that a considerable amount of the absorbing media is contained in the internal structure of this particular glass.

\section{Conclusions}

A study of the transmittance of near-infrared energy by glasses of different compositions has been made from data available in the literature and experimental glasses prepared at this Bureau. The internal transmittance and surface losses of the glasses were calculated for specific wavelengths of radiant energy. It was found that, at certain wavelengths, much of the energy was reflected, scattered, and absorbed by identified groups that occurred at or near the surface of the glass. Other conditions being similar, the total transmittance of a glass for infrared energy, in the range from 2.5 to $5.0 \mu$, varies inversely with the hygroscopicity. This absorption of near-infrared energy may be attributed to the free water in the liquid phase, $\mathrm{OH}, \mathrm{CO}_{3}^{--}$, and $\mathrm{NO}_{3}^{-}$ions, free $\mathrm{CO}_{2}$, and the silicon-oxygen bond.

The authors are indebted to the Radiometry Section for supplying the data on the transmittances of these glasses, and Mason H. Black for this assistance in making some of the glasses. 


\section{References}

[1] W. A. Weyl, Some practical aspects of the surface chemistry of glass, part IV, Glass Ind. 28, 411 (1947).

[2] M. K. Roman, E. E. Marboe, and W. A. Weyl, The influence of heavy metal ions on the hygroscopicity of a glass surface, J. Soc. Glass Tech. 32, 260 (1948).

[3] J. M. Florence, F. W. Glaze, C. H. Hahner, and R. Stair, Transmittance of near infrared energy by binary glasses, J. Am. Ceramic Soc. 30, 328 (1948); J. Research NBS 41, 623 (1948) RP1945.

[4] J. M. Florence, F. W. Glaze, C. H. Hahner, Transmittance of near-infrared energy by some three-component glasses, presented at American Ceramic Society meeting, April 27, 1948, Chicago, Ill. To be published in J. Am. Ceramic Soc.

[5] G. Herzberg, Infrared and Raman spectra of polyatomic molecules (D. Van Nostrand Co., Inc., New York, N. Y., 1945).
[6] J. J. Fox and A. E. Martin, Investigations of infrared spectra $(2.5-7.5 \mu)$. Absorption of water, Proc. Roy. Soc. [A], 174, 234 (1940).

[7] N. E. Dorsey, Properties of ordinary water-substance (Reinhold Publishing Corp., New York, N. Y., 1940).

[8] W. W. Coblentz, Investigations of infrared spectra (Carnegie Institution of Washington, 1906).

[9] C. Schaefer, C. Bormuth, and F. Matossi, The infrared absorption spectrum of the carbonate, $Z$. Physik 39, 648 (1926).

[10] C. Schaefer and C. Bormuth, The infrared absorption of sodium nitrate, Z. Physik. 62, 508 (1930).

[11] A. J. Harrison, Water content and infrared transmission of simple glasses, J. Am. Ceramic Soc. 30, 363 (1947).

[12] H. Rubens, The dispersion of infrared radiation, Wied. Ann. 45, 238 (1892).

[13] E. K. Plyler, Phys. Rev. 33, 48 (1929).

[14] C. J. Phillips, Glass: the miracle maker (Pitman Publishing Co., New York City and Chicago, Ill., 1941).

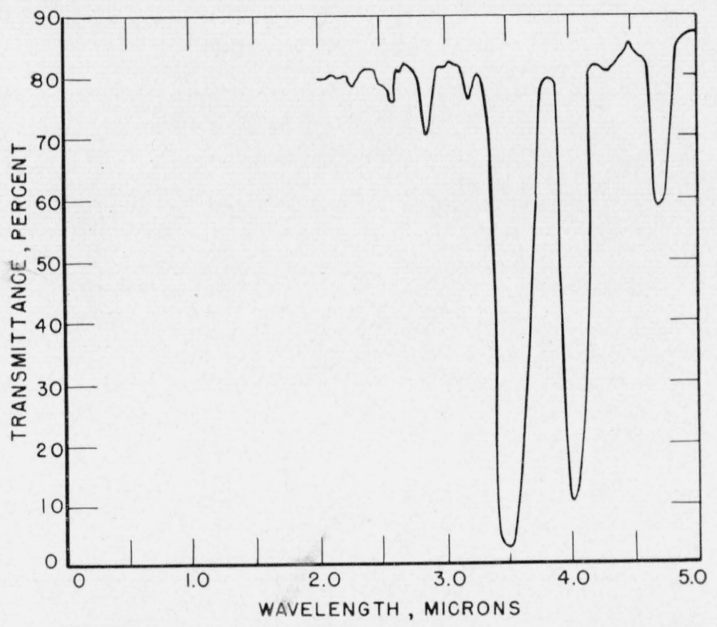

Figure 1. Composite transmittance curve for metal carbonates.

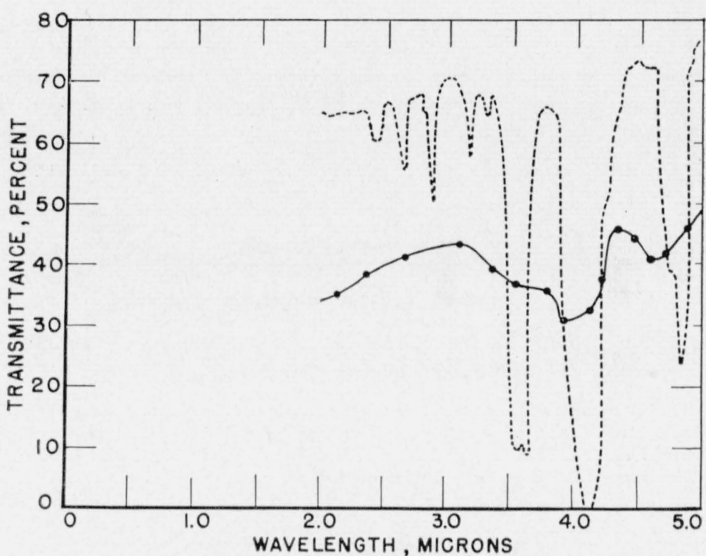

Figure 2. Total transmittance of infrared energy by alkali nitrates.

, $\mathrm{KNO}_{3}$ as determined by Coblentz; $\mathrm{O}, \mathrm{NaNO}_{3}$ as determined by Schaefer, Bormuth, and Matossi.

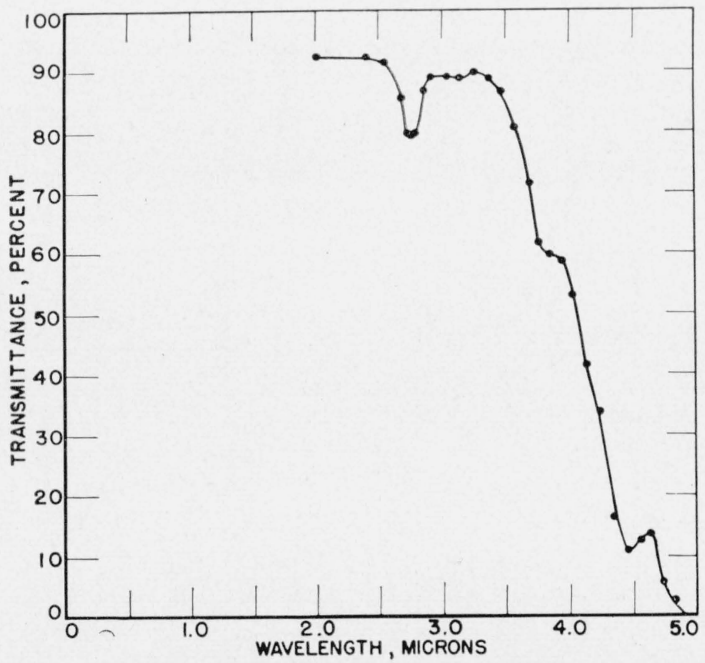

Figure 3. Total transmittance of infrared energy by fused silica.

Thickness of sample $=2.85 \mathrm{~mm}$. 


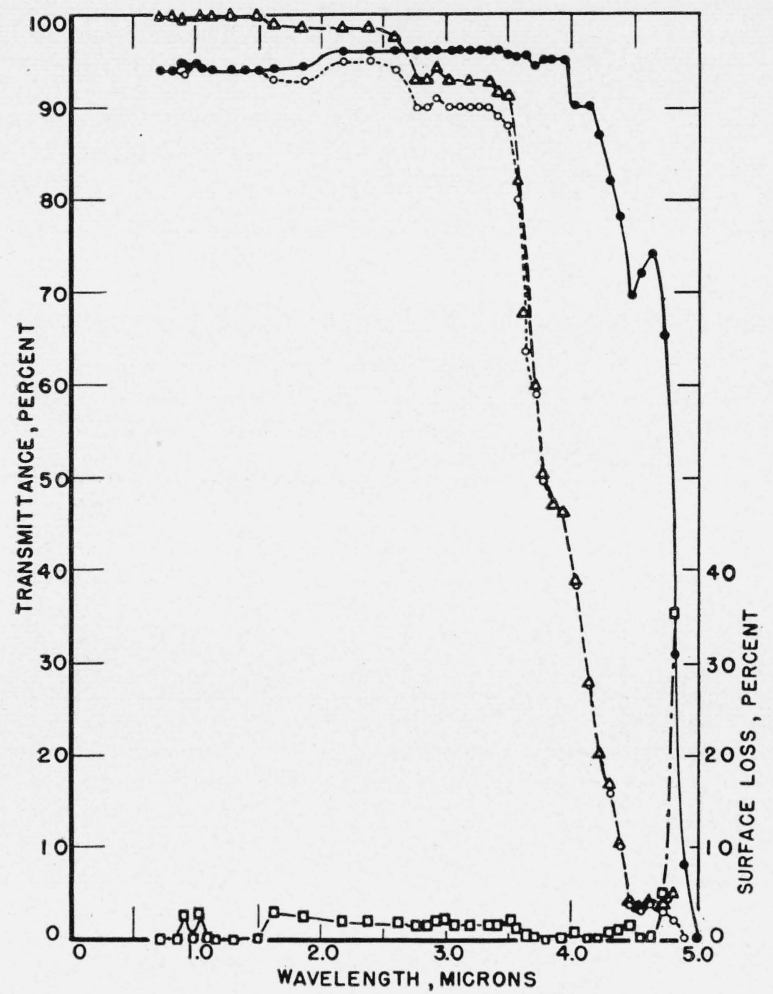

FIGURE 4. Transmittance of infrared energy and surface losses by fused silica for two thicknesses of sample

- Total transmittance, thickness of sample $=0.5 \mathrm{~mm}$. $\bigcirc$, total trans mittance, thickness of sample $=5.0 \mathrm{~mm} ; \Delta$, internal transmittance, equivalent thickness $=5.0 \mathrm{~mm} ; \square$, calculated surface losses, one surface

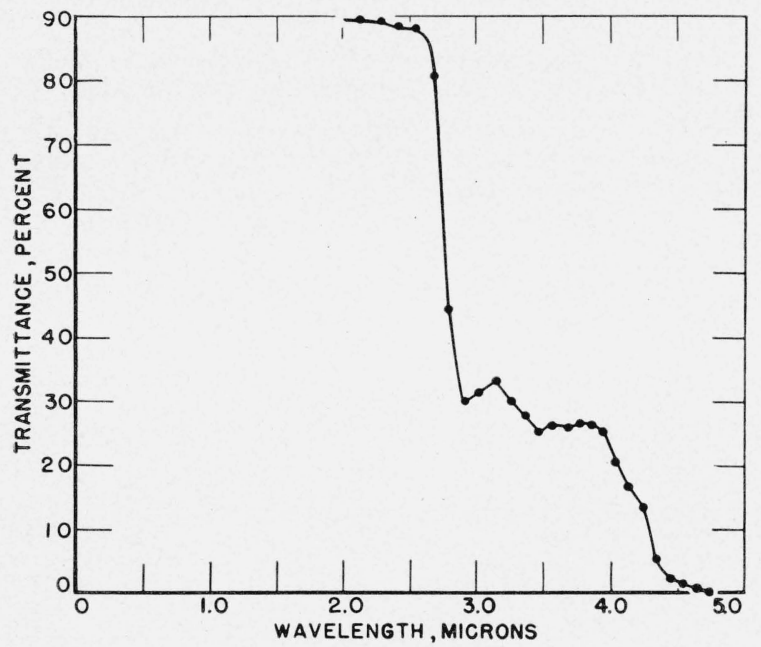

FIGURE 5. Total transmittance of infrared energy by a lithium silicate experimental glass.

Thickness of sample $=5.74 \mathrm{~mm}$.

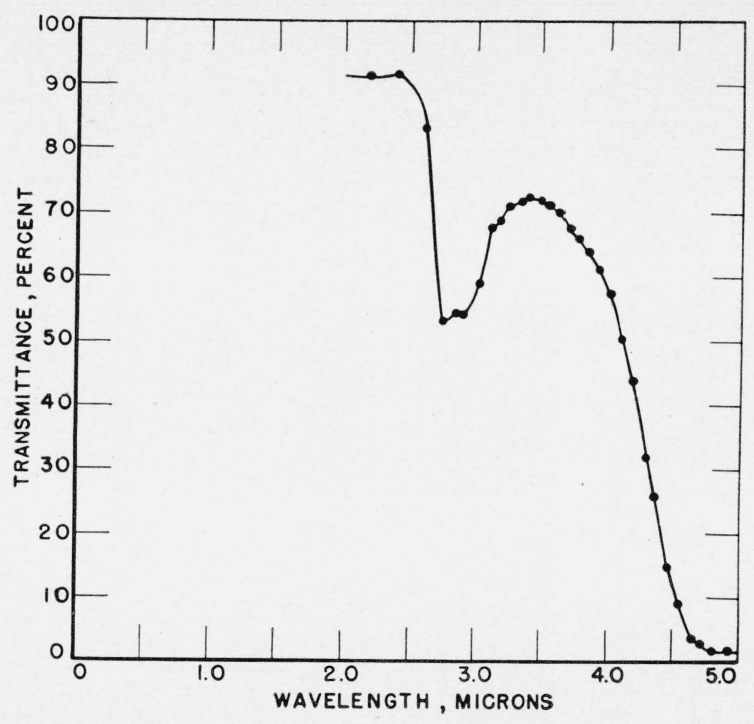

FIgURE 6. Total transmittance of infrared energy by a lithium-beryllium silicate glass.

Thickness of sample $=2.23 \mathrm{~mm}$.

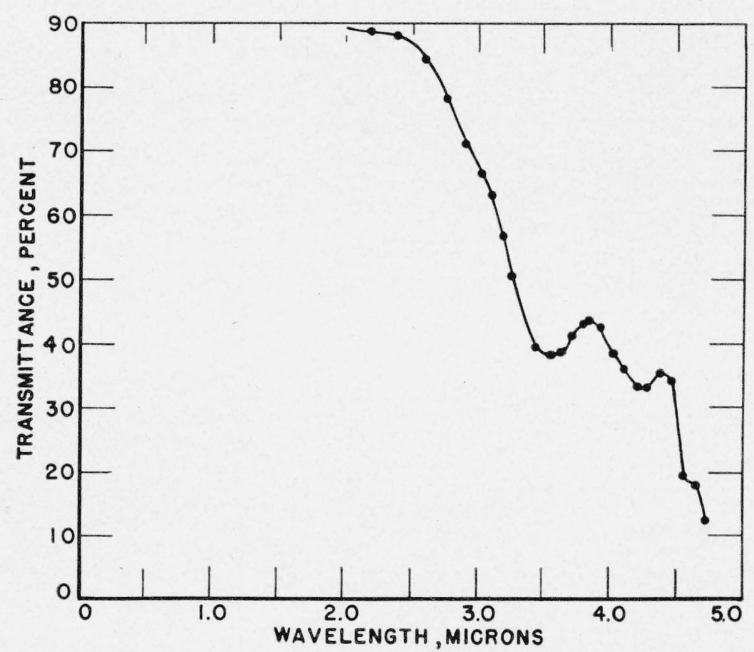

FIgURE 7. Total transmittance of infrared energy by a sodium-barium silicate glass showing a carbon dioxide absorption band at $4.25 \mu$.

Thickness of sample $=2.02 \mathrm{~mm}$. 

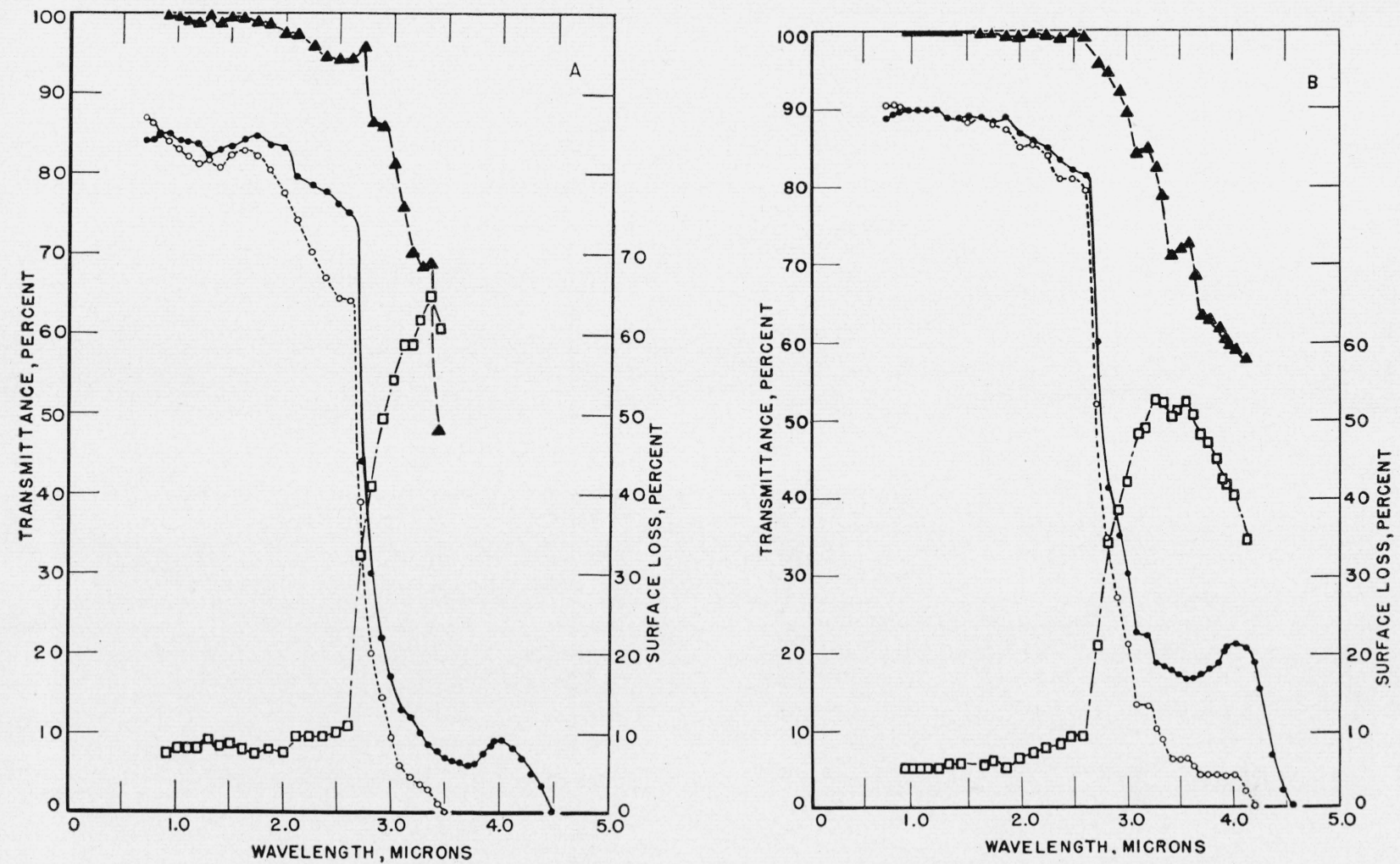

FiguRE 8. Transmittance of infrared energy by a potassium silicate experimental glass for two ihicknesses of the sample; the internal transmittance, and surface losses.

A Made with potassium carbonate; total transmittance, thickness of sample $=2.02 \mathrm{~mm}$; $\bigcirc$, total transmittance, thickness of sample $=7.57$ mm; $\mathbf{\Delta}$,

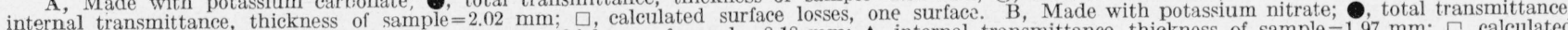

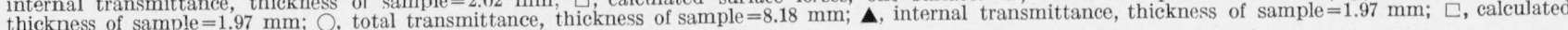
surface losses, one surface.

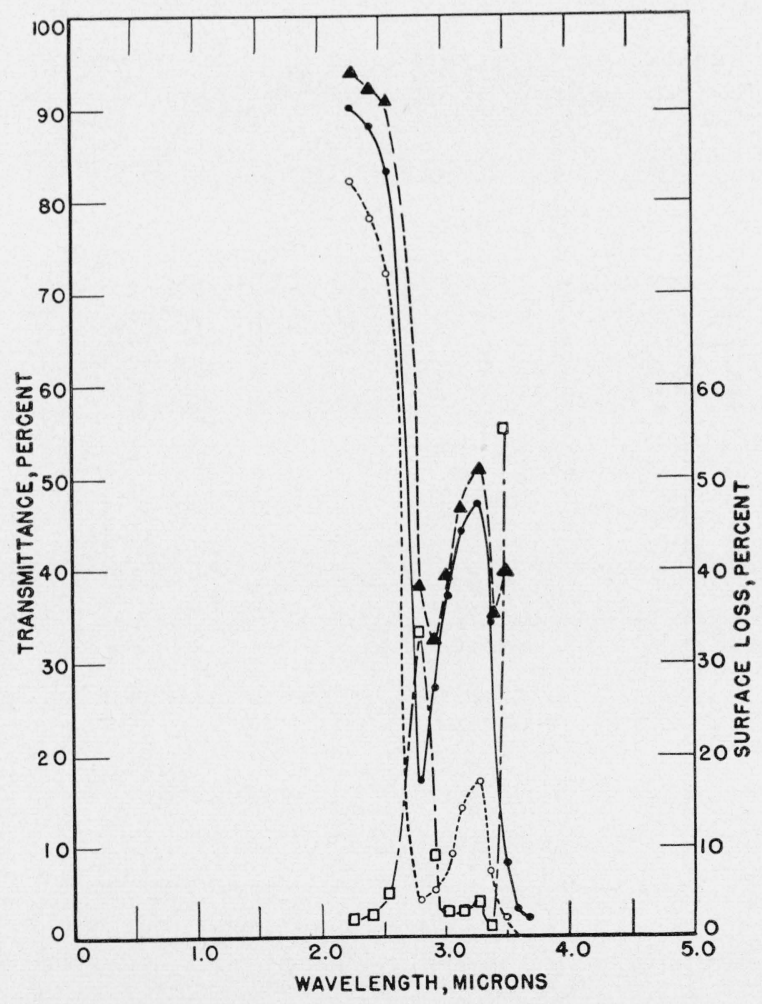

FIgURE 9. Transmittance of infrared energy by untreated Pyrex glass No. 774 .

Total transmittance, thickness of sample $=2 \mathrm{~mm} ; 0$, total transmittance, thickness of sample $=5 \mathrm{~mm} ; \boldsymbol{\Delta}$, internal transmittance, equivalent thickness $=2$ $\mathrm{mm} ; \square$, ealculated surface losses, one surface. 


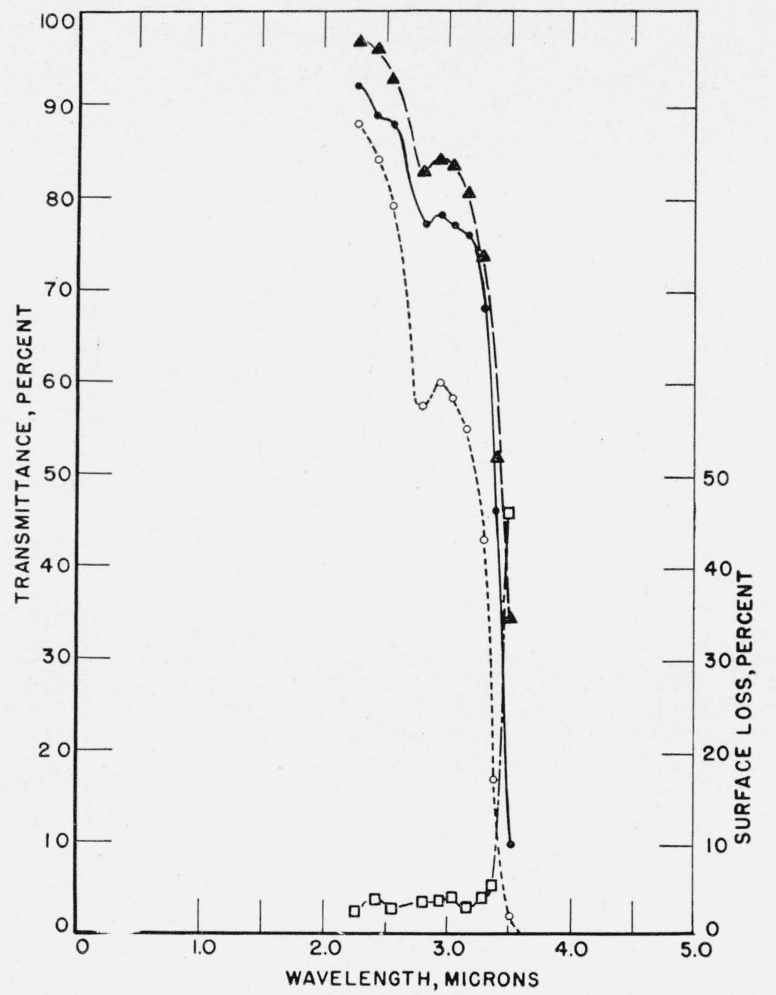

Figure 10. Transmittance of infrared energy by degassed Pyrex glass No. 774 .

Total transmittance, thickness of sample $=2 \mathrm{~mm} ; \bigcirc$, total transmittance,
kness of sample $=5 \mathrm{~mm}$, internal transmittance, equivalent thickness $=2$ thickness of sample $=5 \mathrm{~mm} ; \mathbf{\Delta}$, internal transmi
$\mathrm{mm} ; \mathbf{\Delta}$, calculated surface losses, one surface.

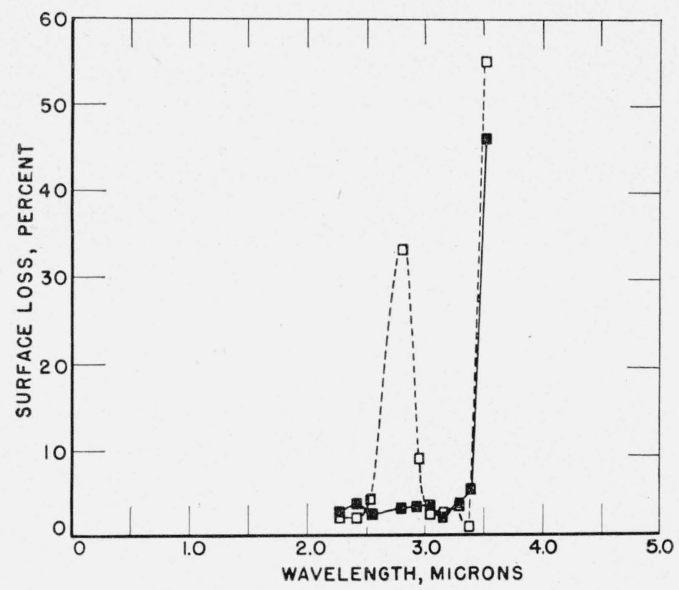

Figure 12. Calculated surface losses, on one surface, of infrared energy by untreated and degassed Pyrex glass No. $77_{4}$.

$\square$, Untreated; $\mathbf{E}$, treated.

FIGURE 13. Transmittance of infrared energy by NBS-IR-1 filter, and surface losses.

, Total transmittance, thickness of sample $=1.08 \mathrm{~mm} ; \bigcirc$, total trans ${ }^{-}$ mittance, thickness of sample $=4.00 \mathrm{~mm} ; \boldsymbol{\Delta}$, internal transmittance, equivalent thickness $=1.08 \mathrm{~mm} ; \square$, calculated surface losses, one surface.

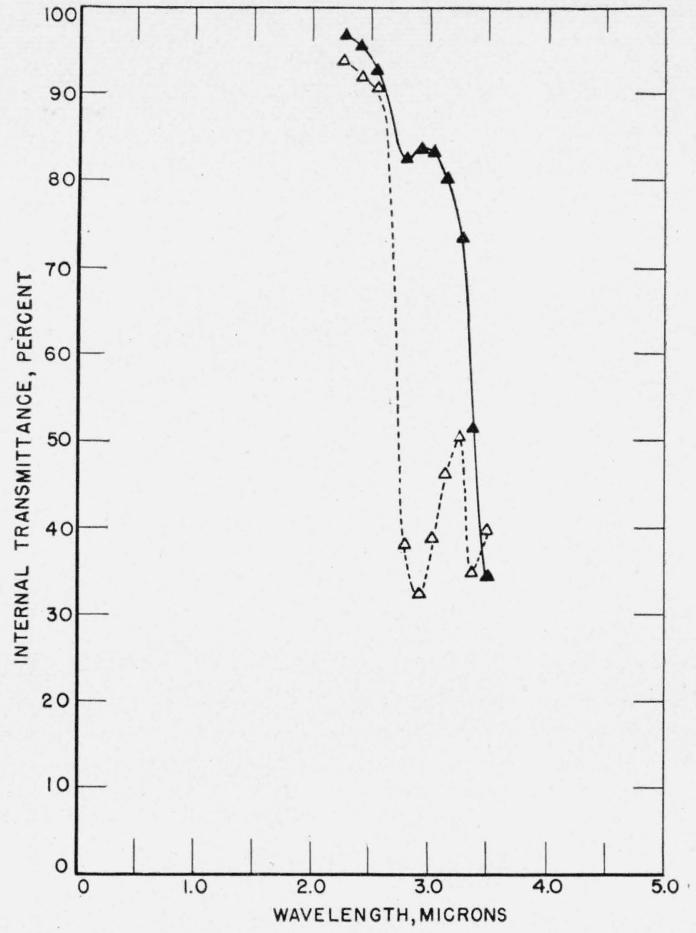

Figure 11. Comparison of internal transmittances of untreated and degassed Pyrex glass No. $7 \% 4$.

$\triangle$, Internal transmittance untreated sample, thickness of sample $=2 \mathrm{~mm}$ : $\boldsymbol{\Lambda}$, internal transmittance degassed sample, thickness of sample $=2 \mathrm{~mm}$.

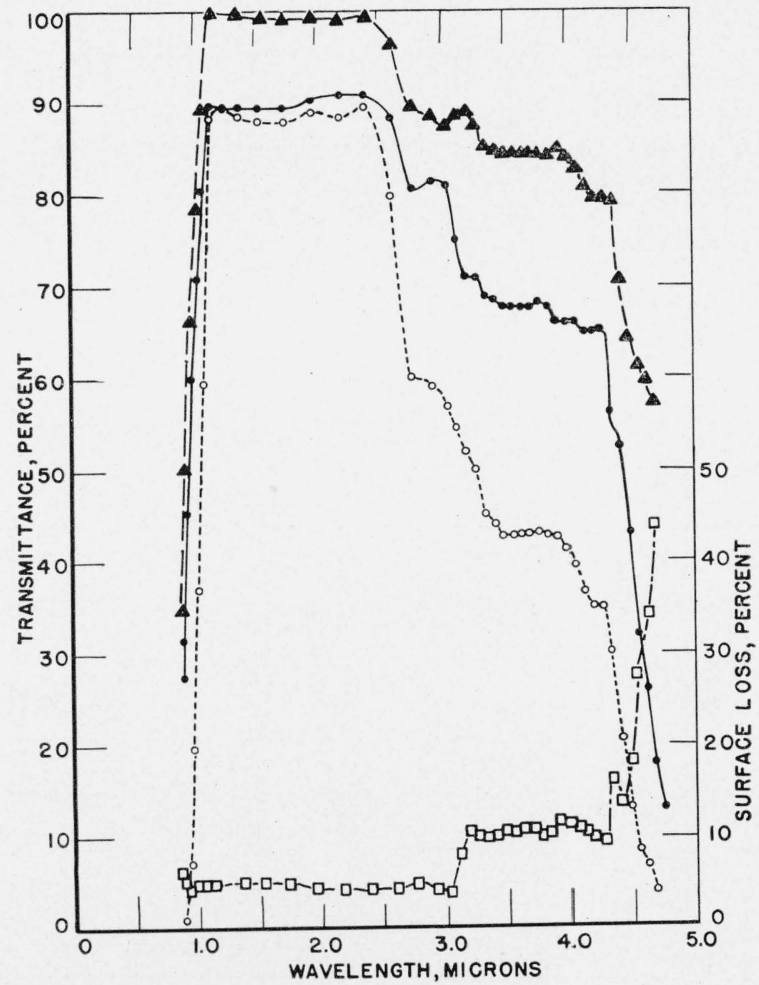

Washington, March 27, 1950. 